\title{
Das Austreiben eines panaschierten Catalpa-Zweiges während der sogenannten «mittleren Ruhe»
}

Seitdem VEGIS ${ }^{1}$ die zahlreichen Ruhezustände bei höheren Pflanzen genauer untersucht und in einer Tabelle zusammengestellt hat, gilt die "mittlere Ruhe" als die Zeit der typischen, wahren Wachstumsruhe, die nicht durch Aussenbedingungen, sondern nur durch verschiedene Frühtreibmittel aufgehoben werden kann. Schon viel früher hatte LAKON ${ }^{2}$ gefunden, dass an teilweise panaschierten Bäumen zuerst die grünen $Z$ weige in den Ruhezustand übergehen, später erst die scheckigen und ganz zuletzt die weissblättrigen. Er nimmt an, ein Überwiegen der organischen Substanzen über die Nährsalze bestimme den früheren Eintritt der Ruhe bei den

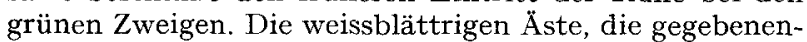
falls ja fast wie ein Parasit der grünen Zweige leben, können niemals die für eine feste Ruhe erforderlichen organischen Substanzen im Überfluss anhäufen. Später hat $\mathrm{LAKON}^{3}$ seine Ansicht wiederholt und durch anatomische und auch experimentelle Befunde an Acer negundo gestützt. Die grünen $Z_{w e i g e}$ sind reich, die weissen aber auffallend arm an organischen Reservestoffen; die grünen $Z$ weige besitzen im Herbst eine deutliche feste Ruhe, während die weissen auszutreiben begannen.

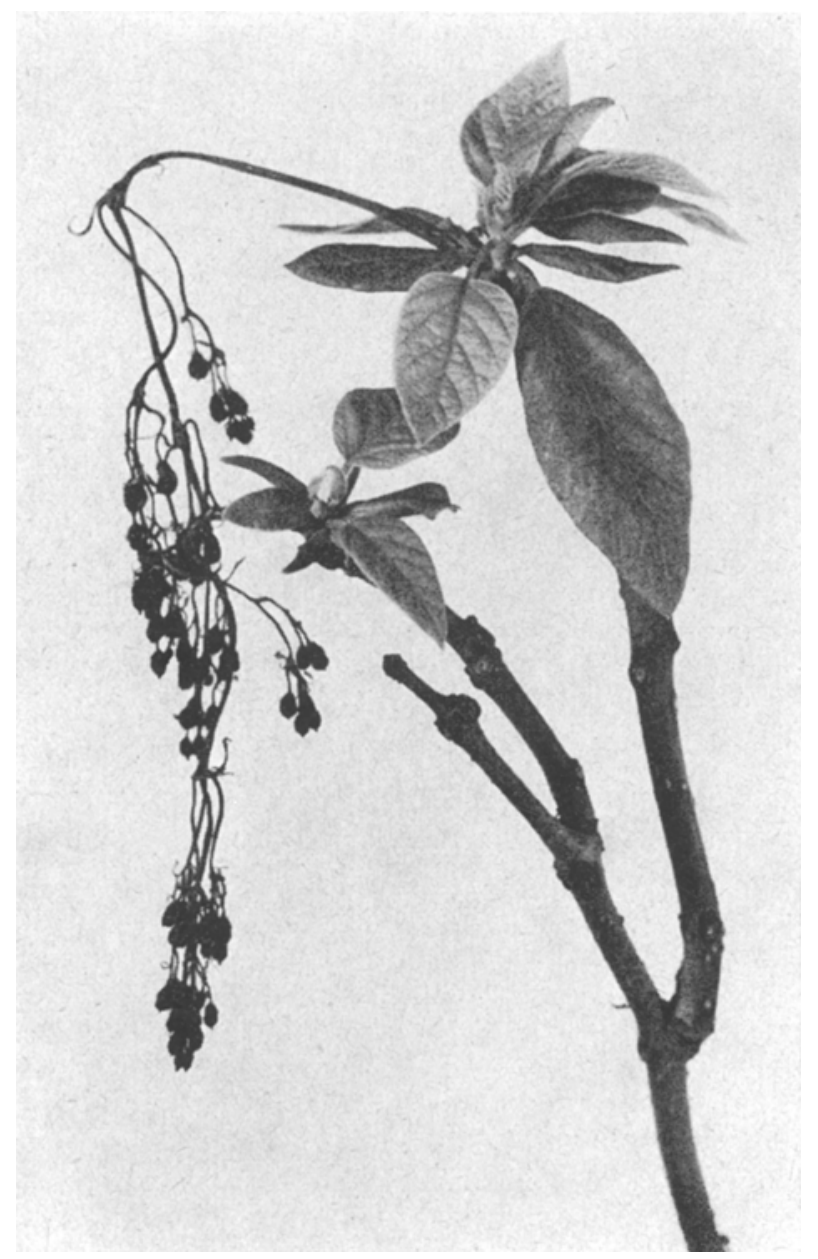

Im Kalthaus austreibender Zweig von Catalpa crubescens f. pulverulenta, mit verwelkten Blutenknospen. Stand vom 15. September 1969.
Matevial und Methode. Es war nun zu untersuchen, ob sich solche Ergebnisse auch im Falle der Panaschüre von Catalpa erubescens feststellen lassen. Während die Blätter der panaschierten Form von Acer negundo beim Pressen für das Herbarium durch keine Purpurfleckenbildung ausgezeichnet sind, tritt die letztere bei der pulverulenta-Form von $C$. erubescens als eine biochemische Besonderheit auf. Arbeiten über die Natur der Verfärbung sind derzeit im Gange ${ }^{4}$.

Von der Versuchspflanze standen also eine normale, nicht panaschierte und eine als $C$. evubescens f. pulverulenta bezeichnete Pflanze zur Verfügung, deren Blätter kleinfleckig panaschiert sind. Beblätterte Zweige beider Pflanzen wurden am 10. Juli 1969 abgeschnitten und im Kühlzimmer unter Dauerlicht durch 38 Tage bei $+4{ }^{\circ} \mathrm{C}$ in wasserdichten Igelitsäckchen aufbewahrt. Dann wurden sie aus den Säckchen genommen und in mit Wasser gefüllten Gläsern in ein Kalthaus gebracht. Die nach einigen Tagen welkenden Blätter wurden beseitigt. Die in der gärtnerischen Praxis üblichen Treibverfahren wurden selbstverständlich nicht angewendet.

Ergebnisse und Diskussion. Bis Ende August zeigten die beiderlei Zweige keine Unterschiede. Aber bereits in den ersten Septembertagen entfalteten sich an den pulvevulenta-Zweigen einige Blättchen, deren Spreiten am 15.9.1969 $49 \times 28 \mathrm{~mm}$ und $47 \times 29 \mathrm{~mm}$ (Figur) und am $6.10 .196955 \times 35 \mathrm{~mm}$ und $53 \times 39 \mathrm{~mm}$ Maximalgrösse erreichten. Dann verloren die Blätter ihren Turgor. Die nicht panaschierten Zweige zeigten keinerlei Austreiben.

Man ersieht daraus, dass der panaschierten C. erubescens f. pulvevilenta im Gegensatz zu der vollgrünen Normalform die feste "mittlere Ruhe" fehlt oder sehr verkürzt ist. Sie verhält sich also ebenso wie $A$ cer negundo. Dadurch wird die Hypothese ${ }^{5}$ gestützt, dass bei panaschierten Zweigen die infolge verminderter Assimilation eingeschränkte organische Substanz bei hohem Angebot anorganischer Nährstoffe das aktive Wachstum entscheidend begünstigt, während Reichtum an Assimilaten bei verhältnismässigem Mangel an anorganischem Material über das Einstellen des Wachstums zu einer echten "mittleren Ruhe" führt.

Résumé. Le repos vrai semble être absent chez la forme pulverulenta de Catalpa erubescens qui diffère des autres espèces ligneuses à feuilles panachées parce qu'elle prend, à la presse botanique, une coloration pourpre.

J. PACLT

Slowakische Akademie der Wissenschaften, Institut für experimentelle Phytopathologie und Entomologie,

Ivanka pri Dunaji (Tschechoslowakei), 1. Dezember 1969.
1 A. Vegis, in Handbuch der Pflanzenphysiologic (Fd. W. RuHLAND, Springer, Berlin, Heidelberg und New York 1965), vol. 15/2, p. 518. 2 G. Lakon, Ber. dt. bot. Ges. 34, 639 (1916).

3 G. Lakon, Ber, dt. bot. Ges. 35, 648 (1918).

4 V. Prouvier, im Druck (1970).

A. Vegrs, in Handbuch der Planzenphysiologic (Ld. W. RUHLAND; Springer, Berlin, Heidelbcrg und New York 1965), vol. 15/2, p. 608. 